\title{
Method to eliminate patient breath induced lens fogging with mask use during indirect ophthalmoscopy
}

(c) The Author(s), under exclusive licence to The Royal College of Ophthalmologists 2021

Eye (2022) 36:1706-1707; https://doi.org/10.1038/s41433-021-01806-5

\section{TO THE EDITOR:}

The COVID-19 pandemic has had a profound effect on almost every aspect of ophthalmology practice and we have seen many amendments to the way we work as highlighted in the adaptations made by the COVID-19 Urgent Eyecare Service initiative in Manchester [1] The use of face coverings/masks has become ubiquitous; however, they have introduced new problems. Patients have experienced more ocular surface disease [2] and spectacle lens fogging [3]. Examination of patients by ophthalmologists has become more troublesome. During slitlamp-based indirect ophthalmoscopy, we have experienced fogging/misting of the condensing lens by the patient's redirected breath. To facilitate an adequate view and eliminate lens fogging, some practitioners invite the patient to temporarily remove their mask, and thus remove the protection the mask may have provided for the clinician from any respiratory viruses the patient may be carrying.

However, we employ a simple technique applicable for all interactions for patients wearing face masks. The fundamentals are the same as in normal examination: holding the condensing lens between the thumb and index finger; the middle finger can be used to elevate the upper eyelid when needed. Crucially, however, with this technique, the ring finger is used to apply posterior pressure to the superior border of the mask, compressing it gently against the patient's cheek and eliminating the upward stream of their breath responsible for the fogging of the lens (Fig. 1A). The middle finger can still be used to elevate the upper lid when needed, such as during downgaze (Fig. 1B). In our experience, this has been an effective and simple intervention. The additional benefits of this includes maintaining the protection of the examining clinician when adequate physical distancing cannot be maintained, and reassurance for the patient that every endeavour is being made to adhere to public health guidance and good practice.

Reducing lens fogging with this technique will not only provide a better view for clinical examination but also provide additional
(A)

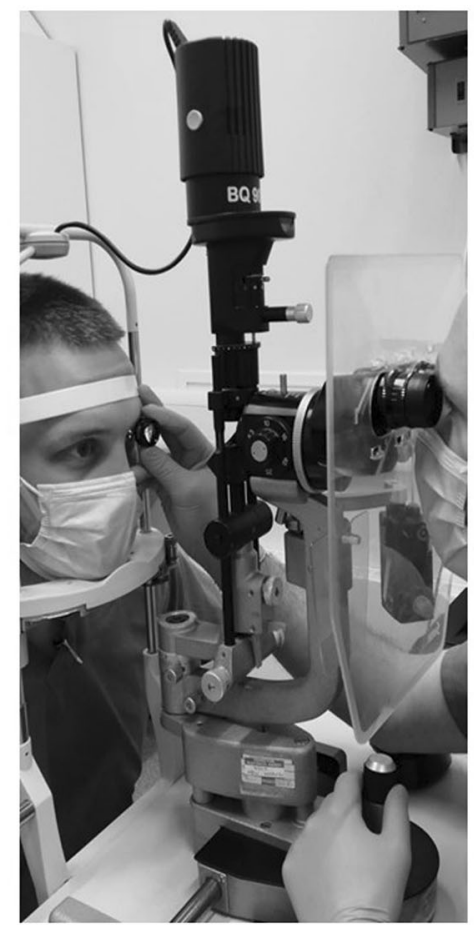

(B)

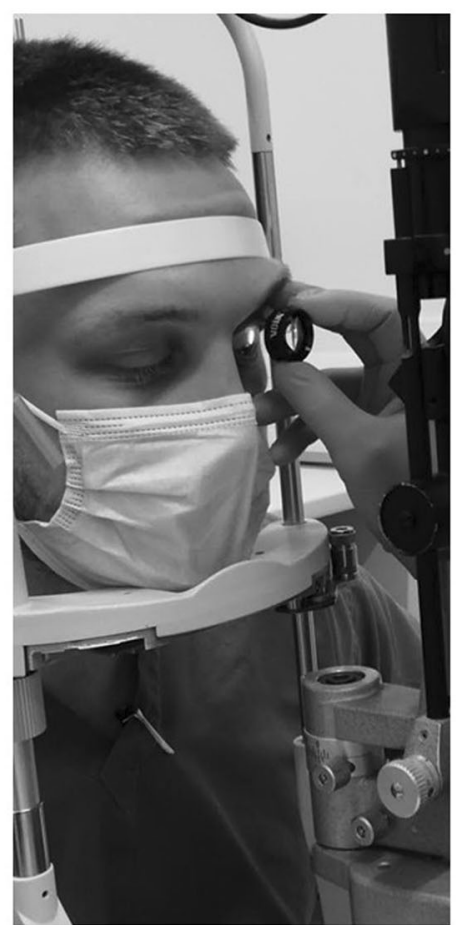

Fig. 1 A demonstration of the application of gentle posterior pressure on the superior border of the face mask to reduce lens fogging in primary position of gaze (A) and in downgaze using the middle finger to elevate the upper eyelid (B). 
protection for healthcare workers to reduce their risk of acquiring SARS-CoV-2 in the workplace, and the impacts this may have on staffing levels in a pressured health care system.

Francis W. B. Sanders $\mathbb{D}^{1}$ and Colm McAlinden $\mathbb{D}^{1,2}{ }^{凶}$ ${ }^{1}$ Department of Ophthalmology, Singleton Hospital, Swansea Bay

University Health Board, Swansea, UK. ²Department of Ophthalmology, Royal Gwent Hospital, Aneurin Bevan University Health Board, Newport, UK. ${ }^{凶}$ email: colm.mcalinden@gmail.com

\section{REFERENCES}

1. Kanabar R, Craven W, Wilson H, Rietdyke R, Dhawahir-Scala F, Jinkinson M, et al. Evaluation of the Manchester COVID-19 Urgent Eyecare Service (CUES). Eye. 2021;1-9. https://doi.org/10.1038/s41433-021-01522-0.

2. Chadwick O, Lockington D. Addressing post-operative Mask-Associated DryEye (MADE). Eye. 2021;35:1543-4. https://doi.org/10.1038/s41433-020-01280-5.

3. Agarwal P, Sharma D. How to Prevent Fogging of Spectacle Glasses When Wearing a Face Mask. Indian J Surg. 2021;1-2. https://doi.org/10.1007/s12262-021-02729-x.
AUTHOR CONTRIBUTIONS

FS wrote the main body of the text, aided with the photography for Fig. 1 and prepared the manuscript for submission, $\mathrm{CM}$ edited the text and provided the photographs for Fig. 1

\section{COMPETING INTERESTS}

The authors declare no competing interests.

\section{ADDITIONAL INFORMATION}

Correspondence and requests for materials should be addressed to Colm McAlinden.

Reprints and permission information is available at http://www.nature.com/ reprints

Publisher's note Springer Nature remains neutral with regard to jurisdictional claims in published maps and institutional affiliations. 